\title{
Innovative Design of Traffic Lighting System Based on The Wind/PV Hybrid Generation
}

\author{
Bing Li \\ School of Mechanical Engineering, Baicheng Normal University, Baicheng City, Jilin province, 137000, \\ China
}

Key words: Wind/PV Hybrid; Traffic; Lighting system;Innovative design

\begin{abstract}
With the development of social economy in recent years, the consumption of energy is increasing day by day. And with the increasingly scarce resources of the earth, the rising cost of basic energy investment has led to various security and pollution risks. The wind and solar energy of the earth have been widely regarded as one of the most ideal pollution-free and green energy sources, and the related technologies have been fully developed in recent years. Wind/PV Hybrid technology overcomes the limitations of the single use of the two energy sources, and will be an important direction for the research and application of new energy resources. Based on the author's learning and practical experience, this paper first analyzed the structure and principle of the Wind/PV Hybrid lighting system, and then put forward the innovative design of the Wind/PV Hybrid street lamp in a certain area.
\end{abstract}

\section{Introduction}

With the rapid growth of China's economy in recent years, the contradiction between supply and demand of energy is becoming increasingly apparent. In some coastal cities, the gap of energy supply is large. Therefore, it is urgent to improve the efficiency of energy saving and emission reduction and municipal lighting equipment. Street lighting is an important component of urban lighting and the general street lamps are made of high pressure sodium lamp and low pressure sodium lamp. But the light source of sodium lamp is 360 directional light emitting, and the light loss is big, and the light efficiency is not too high. Therefore, the study of the use of new energy-saving, efficient, environmental, semiconductor and light-emitting LED street lamp with high color rendering index is of great significance to the energy saving of urban lighting. LED lighting equipment has the main advantages of good driving characteristics, fast response, directional light emitting, low power consumption, high seismic resistance, long service life and so on. The advantages of LED light sources have been demonstrated in many engineering applications and lighting. Semiconductor lighting will become an alternative to traditional light sources and become a new generation of energy-efficient light sources. Therefore, the LED light source applied to street lighting will improve the efficiency of energy utilization and save energy.

\section{The Structure and Principle of the Wind/PVH Hybrid Lighting System}

Brief introduction of system. The Wind/PV Hybrid Generation System consists of a wind generator, a solar cell square, an intelligent controller, a battery pack, a multi-function inverter and an auxiliary component. The system will store the power stored in the battery through using the solar cell square and the wind power generator. When the user needs to use electricity, the inverter converts the DC stored in the storage battery into alternating current and transport it to user through electric transmission line. This is the common power generation including wind power generator and solar cell phalanx. Wind/PV Hybrid street lamps use natural wind and solar power to generate electricity with dual advantages of wind and solar energy and make use of solar cells when there is no wind. When there is no wind, the wind can generate electricity through a wind generator. When the wind and PV is available, the utility model can generate electricity at the same time, and the 
power generation can be stored in the storage battery, and the power supply is provided by the storage battery for the light source when running, so that the light source can shine. Lighting equipment for the road, mainly composed of the wind turbine, solar cell components, lamp poles, controllers, batteries and light sources.

The working principle of Wind/PV Hybrid street lamp. The Wind/PV Hybrid Generation System is a device that converts wind energy and light energy into electrical energy. It works by using natural wind as the power and the wind wheel absorbs the energy of the wind, driving the wind-driven generator to rotate and transforming the wind energy into the electric energy. Further, It is rectified by the controller with the voltage stabilizing effect, and transforms the alternating current to the direct current, so that to charge and store electrical energy to a battery. The photovoltaic effect is used to convert solar energy directly into direct current for load use or storage in the storage battery, and it is shown in Figure 1.

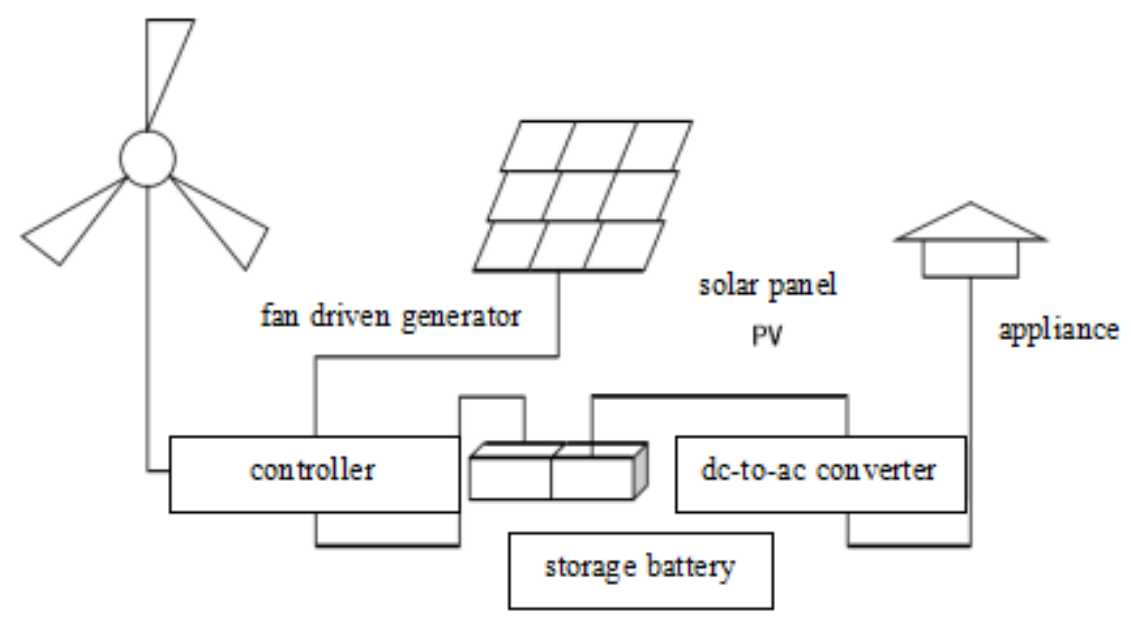

Fig. 1 the working principle of the Wind/PV Hybrid street lamp

\section{Innovative Design of Wind/PV Hybrid Street Lamp Design in a Certain Area}

Design method of Wind/PV Hybrid lighting system. The design of the Wind/PV Hybrid lighting system refers to the selection and verification of the relevant system parts with reference to the urban road lighting design standards, and city night lighting design specifications. According to the experience of other projects that already built, the energy storage system of the Wind/PV Hybrid lighting system in this area uses the maintenance free lead-acid battery, and is equipped with the corresponding power electronic device to supply power to the street lamp. Then we calculate the standby days of the electric energy according to the power consumption of the selected light source and the longest continuous cloudy days in the area.

Design of Wind/PV Hybrid street lamp. According to the urban road lighting design standards, we choose integrated LED lamps of $24 \mathrm{~V} / 100 \mathrm{~W}$ and $24 \mathrm{~V} / 40 \mathrm{~W}$ each. As the roads are wider, the fixtures are arranged symmetrically and bilaterally. An important indicator of the load is the daily average electricity consumption, and the daily electricity consumption can be calculated according to the time of the street lamp. The calculation of daily consumption: $\mathrm{W}=\mathrm{P} \times \mathrm{N}$.

In the formula, $\mathrm{W}$ is the load daily electricity consumption, and unit is wh; $\mathrm{P}$ is the load rated power, and its unit is $\mathrm{W}$; $\mathrm{W}$ is the load average daily working hours, its unit is $\mathrm{H}$.

According to the sunshine situation in the area, two lamps automatically open after dark. After 5 hours' work, the lamp power is automatically changed to half power until daylight. The Wind/PV Hybrid street lamps are converted to full power during the winter. The working time is 9 hours. Considering the continuous days of the system, the power of the battery can be quickly replenished. We specially designed 1.3 times the power consumption of the system to design the surplus of the system power consumption. The total daily electricity consumption of the Wind/PV Hybrid street lamps system is:

$$
(100+40) \mathrm{Wx} 9 \mathrm{~h} \times 1.3=1638 \mathrm{Wh}
$$


The daily power consumption of the system is QL:

$$
Q_{L}=\frac{W t}{U_{L}}
$$

In this formula, Wt is the total daily power consumption of the system, and UL is operating voltage for the system; V; Q; system daily power consumption:Ah.

The daily capacity of the designed street lamp can be calculated as follows:

$$
Q_{L}=\frac{W t}{U_{L}}=\frac{1638}{24}=68.25 \mathrm{Ah}
$$

When the capacity of the Wind/PV Hybrid street lamps is not matched with the output power of the small wind power generator, serious problems will appear. When the capacity of the selected storage battery is too large, the output power of the wind generator can not complete the charging work of the battery in time, and the battery will be in a state of short supply. This will greatly shorten the service life of the battery, affecting the operation of the street lighting system; similarly, when the capacity of the selected battery is too small, the battery will be over charged, and the service life of the battery will also be affected. Therefore, the capacity selection of the battery is very important, and the storage battery of the corresponding capacity must be selected after calculation and verification. In the absence of wind or sun, the equipment can not generate electricity, and completely rely on the battery power supply, then the power supply room is:

$$
H=\frac{C \times 12 V \times 0.8 \times 0.9}{P L}=30.9 h
$$

So spare days: 0.9 hours $\div 9$ hours / day $=3.43$ days

The storage capacity of $\mathrm{Cb}$ is mainly determined by the number of standby batteries and the daily consumption capacity of the system. The relationship is as follows:

$$
C b=\frac{\alpha \times Q_{L} \times n \times \beta}{C}
$$

In this formula, $\mathrm{Cb}$ is the battery capacity, Ah; alpha is the safety factor, and general is 1.1-1.2;

$\mathrm{QL}$ is the system daily power consumption, $\mathrm{Ah} ; \mathrm{N}$ is the battery standby days or the maximum continuous rainy days; $\beta$ is the coefficient of temperature correction; $\mathrm{C}$ is the maximum discharge depth of the battery;

Then, for the region, the safety factor is 1.2; the $\mathrm{W}$ under 0 degrees in this area is for a short time; but for the sake of insurance, the temperature correction factor is selected 1.1, the maximum discharge depth of the accumulator is selected 75., and the capacity of the accumulator is:

$$
C b=\frac{\alpha \times Q_{L} \times n \times \beta}{C}=480.48 A h
$$

Through the calculation, the Wind/PV Hybrid street lamps batteries in the area are divided into 2 sets: maintenance free lead-acid batteries, and capacity margin is considered when the capacity is selected

Design of lightning protection for street lamp. According to statistics of climate data, the number of thunderstorm days in the area reached 69 days in 2009, which belongs to areas with more thunderstorms. Therefore, it is necessary to take into account the lightning protection of street lamps. Lightning is a common phenomenon in nature, and it is mainly because the clouds with thunder and lightning or earth potential gradient, so that to cause intense instantaneous discharge. When the discharge is generated between the earth and the thunder, the earth will bring huge discharge current and threat equipment and human body safety. Lightning is very high voltage, and usually up to 10 million volts; while the lightning current can reach several or even several thousand amperes. Therefore, for the street lighting system, it is necessary to install the dedicated lightning protection fittings. According to the characteristics of the region, the location of Wind/PV Hybrid street lamps installation location for both sides of the road is very spacious, and the lamp is used in metal products with the height of $12 \mathrm{M}$ as the highest around the area, so the possibility of being struck by lightning pole is very high. For road lighting, lightning will be a very big threat, and it is also one of the important factors that affect the life of the lighting system. If there is a lightning strike, the street 
lamp is usually damaged directly, and it may even cause a fire. However, we know that the street lights is in the green belt, so if the fire spread to vegetation and other flammable substances, it will seriously threaten the safety of passing vehicles and personnel, resulting in unexpected consequences. The area installed by the street lights are equipped with spherical lightning protection device, and can effectively prevent natural lightning. It meets the lightning protection standards in the national standard of lightning protection GB5005794.

\section{Summary}

Wind energy and solar energy technology is becoming more and more mature, large-scale and industrialized. Independent wind energy and solar energy have disadvantages of their exploitation and utilization. And the combination of complementary wind power and solar power can achieve the most reasonable use of these two new energy technology solutions. At present, the cost of the storage battery accounts for about 30\% of the whole Wind/PV Hybrid street lamps system, and it is the shortest component in the whole system, and it needs to be replaced every 5 years or so. The problems about how to make the battery use longer and how to effectively reduce the cost of storage battery in the whole system become lower than that of our own. It is our urgent problem to solve.

\section{References}

[1] Hai Yan, Wind/PV Hybrid Generation--- Transformation of Lighting System in a Coal Mine Industrial Park[J]. Journal of Chuzhou Vocational and Technical College, 2017, (02): 61-63.

[2] Li Shasha, La Shengcheng, Jia Hongrui. Design of Wind/PV Hybrid LED Intelligent Energy-saving Lighting System[J]. Science and Technology, 2015, (12): 82.

[3] Fu Jing, Jiang Guangjun, Li Dan, Huang Dan. Design of Wind/PV Hybrid LED Intelligent Energy-saving Lighting System[J]. Journal of Chifeng University (Natural Science Edition), 2014, (23): 47-48.

[4] Wang Ting. Research and Development of Small Scale Wind/PV Hybrid Generation Lighting System[J]. Modern Industrial Economy and Information Technology, 2012, (24): 56-58.

[5] Luo Penghui, Liu Mengting. Research Based on Wind/PV Hybrid LED Intelligent Energy-saving Lighting System[J]. Industrial Control Computer, 2011, (11): 109-110.

[6] Hu Yonghua. Development of Controller for Wind/PV Hybrid Street Lamp[D]. South China University of Technology, 2010.

[7] Liu Xiang, Su Jianhui. Design of Small Independent Wind/PV Hybrid Lighting System[J]. Solar Energy, 2010, (02): 22-23. 